Article

\title{
Prioritizing Enabling Factors of IoT Adoption for Sustainability in Supply Chain Management
}

\author{
Sittiporn Pimsakul ${ }^{1}$, Premaratne Samaranayake ${ }^{2}$ and Tritos Laosirihongthong ${ }^{3, *}$ \\ 1 Department of Industrial Engineering, School of Engineering, King Mongkut's Institute of Technology \\ Ladkrabang, Bangkok 10520, Thailand; sittiporn.pi@kmitl.ac.th \\ 2 School of Business, Western Sydney University, Penrith, NSW 2751, Australia; \\ P.Samaranayake@westernsydney.edu.au \\ 3 Department of Industrial Engineering, Thammasat School of Engineering, Thammasat University, \\ Pathumtanee 12121, Thailand \\ * Correspondence: 1tritos@engr.tu.ac.th
}

Citation: Pimsakul, S.;

Samaranayake, P.; Laosirihongthong, T. Prioritizing Enabling Factors of IoT Adoption for Sustainability in Supply Chain Management. Sustainability 2021, 13, 12890. https://doi.org/ $10.3390 /$ su132212890

Academic Editor: Alessio Ishizaka

Received: 21 October 2021

Accepted: 17 November 2021

Published: 22 November 2021

Publisher's Note: MDPI stays neutral with regard to jurisdictional claims in published maps and institutional affiliations.

Copyright: (c) 2021 by the authors. Licensee MDPI, Basel, Switzerland. This article is an open access article distributed under the terms and conditions of the Creative Commons Attribution (CC BY) license (https:// creativecommons.org/licenses/by/ $4.0 /)$.

\begin{abstract}
Several studies have reported on enabling factors of IoT adoption, emphasizing the importance of key factors for successful IoT adoption. However, only a few studies have investigated enabling factors with consideration of a sustainability perspective and no similar study has focused on manufacturing from an emerging economy perspective. The main purpose is to investigate enabling factors of IoT adoption from a sustainability perspective. This study aims to (i) identify and select key enabling factors from a comprehensive literature review, and (ii) prioritize them using a multiple criteria decision-making approach, validated through industry experts' opinions. The results showed that system integration and IoT infrastructure are the top enabling factors in increasing the overall success of IoT adoption. Furthermore, enabling factors of IoT adoption are directly connected with organizational resources/technological capabilities that support the resource-based view theory. Supply chain managers can use the findings of this study to guide and prioritize IoT adoption, and develop strategies for going forward with IoT settings, using the relative importance of enabling factors and interdependencies among them from the technological and organizational perspectives. To generalize these findings through benchmarking of enabling factors in manufacturing, a broader range of industries within the manufacturing sector should be considered in future studies.
\end{abstract}

Keywords: IoT adoption; IoT systems; supply chain responsiveness; system integration; IoT infrastructure

\section{Introduction}

With the increasing emphasis on sustainability in supply chain management under a highly competitive marketplace and globalization, manufacturing companies are under pressure to constantly evolve their production systems with a sustainability focus and meet the uncertain and rising customer expectations in a cost-effective manner. The term Industry 4.0 or the Fourth Industrial Revolution, coined in Germany in 2011 [1], is an emerging industrial ecosystem and probably an enabler to the current competing conditions. Industry 4.0 is based on the horizontal and vertical integration of production systems driven by real-time data interchange among machines, equipment, products, and people for increased automation, improved communication and self-monitoring, and production of smart machines without human interruption [2]. It creates sustainable business opportunities, including increasing product and process flexibility, productivity, quality, and reliability, shortening time to market, and improving efficient resource utilization [3]. Various growing industrial developments associated with broader Industry 4.0 consist of cyber-physical systems (CPS), the Internet of Things (IoT), the Internet of Service (IoS), robotics, Big Data analytics, artificial intelligence (AI), Cloud computing, and 3D printing [4]. 
The Internet of Things (IoT), also known as the Industrial Internet of Things (IIoT), is considered one of the crucial pillars of Industry 4.0 [5]. IoT also represents one of the most disruptive technologies. It can be defined as a network of hardware, software, devices, databases, objects, sensors, and systems, all working at the service of supply chain partners [6]. IoT facilitates the combination of intelligent machines, advanced predictive analytics, and machine-human collaboration, leading to increased productivity, efficiency, effectiveness, and reliability at a manageable cost [7]. Adopting IoT in production systems and supply chain processes (i.e., purchasing, transportation, and warehousing) and also in a wide range of industries/applications such as retailing, healthcare, energy and utilities, home appliances, heavy equipment, and education is expected to increase at a rapid rate [8]. IoT is one of the most promising technologies to control and improve the performance of the supply chain. Benefits of using IoT in supply chain management functions include a highly visible supply chain, better communication, increase of product and service quality, reduction in excessive products and costs, faster response to changing customer needs or supplier availability, more optimization of shipments, and the assurance of complete deliveries [9].

The incorporation of information and communication technologies resulting from IoT adoption has made production systems and supply chain processes more intelligent and sustainable [10]. To reach sustainable business opportunities, a balance of economic, environmental, and social performance is required [11]. Sustainable supply chain in IoT adoption should be addressed in an integrated approach from its three perspectives: economic benefits, environmental conditions, and social needs, also known as the triple bottom line (TBL) of sustainability [12]. Sony and Naik [13] mentioned that Industrial 4.0 or IoT adoption is considered sustainable if it balances the economic benefits, environmental conditions, and social needs of present and future generations. However, some manufacturing organizations or industries may consider only one or two of these three perspectives for their supply chain sustainability. For example, the adoption of Industrial 4.0 (I4.0) technologies in manufacturing has substantially focused on economic sustainability, competitiveness, and growth [14]. De Sousa Jabbour et al. [15] concentrated on environmental sustainability and identified the need for balancing I4.0 technologies and environmental sustainability. Various strategic plans that have adopted sustainability as part of their objectives include "Industrie 4.0", “Made in China 2025”, “Making Indonesia 4.0”, “Taiwan Productivity 4.0", and "Thailand Sustainable Smart Industry, MSIE 4.0" [16].

The impact on the economic dimension of TBL is the result of improved process flexibility, efficiency, and effectiveness through the new way of producing goods and optimizing the supply chain. Manufacturing companies using sensors in the production line enhance economic sustainability through improved inventory and warehouse management [17]. Moreover, IoT systems improve the efficiency and effectiveness of supply chain management by reducing inventory inaccuracy and the time to market. In terms of the impact on the environmental dimension, the primary aspect is the improvement of sustainable utilization of resources resulting from the capability to analyze and forecast production performance [18]. For instance, recycling and regeneration of resources, redesign of processes and products to minimize resource usage, and replacement of non-renewable with renewable resources can be achieved by IoT applications [19]. The real-time data generated by the IoT sensors is analyzed with a mathematical model to achieve cost reduction and to manage the remanufactured resources [20]. The impact on the social dimension of TBL primarily comes from a safer workplace, leading to the reduction of safety incidents and the increased morale of the employees [17]. For example, the increased automation by the use of robotics and other emerging digital technologies creates better labor conditions, job satisfaction, and higher quality of life for employees [21].

The organization benefits from IoT in different ways from improving the efficiency of the organization (i.e., real-time tracking and tracing of the product, better resource utilization, and better inventory management) to increasing customer satisfaction. However, research shows that several IoT adoption initiatives have failed. Therefore, many researchers 
have attempted to identify the critical success factors, enabling factors, or barriers for IoT systems. In present literature, few researchers have used a multiple case study approach to determine barriers or enabling factors to IoT adoption and some researchers have utilized statistical tools, such as hierarchical logistics regression analysis, structural equation model, or exploratory factor analysis, and multiple criteria decision-making (MCDM) techniques to prioritize the selected enabling factors impacting IoT application [22]. Lin [23] has implemented Fuzzy Delphi and Fuzzy analytic hierarchy process (AHP) techniques to ascertain the key factors to utilize radio frequency identification (RFID) technology in Taiwan logistics industries. Hsu et al. [24] has conducted a systematic study for Taiwan logistics industries using a decision-making trial and evaluation laboratory (DEMATEL) technique to evaluate factors influencing IoT adoption. Moreover, some other researchers have conducted empirical research studies on barriers or drivers to Industrial 4.0 or IoT adoption in specific or various country contexts. For example, barriers or hindrances for IoT adoption in the Indian manufacturing industry were identified [22,25]. Maisiri et al. [1] studied factors inhibiting sustainable adoption of Industry 4.0 in the South African manufacturing industry. Stentoft et al. [26] determined drivers and barriers to Industry 4.0 readiness and practice in Danish SME manufacturers in Denmark. However, most research studies have focused on the barriers or enabling factors for IoT adoption without the consideration of supply chain sustainability. Several studies have shown/ stated that some of the enabling factors that have been prominent in mature/experienced companies may not be prominent or considered important if IoT adoption is in the early stage of diffusion $[1,6,10,22]$.

Based on the research gaps outlined above, the main objective of this research is to enlist and prioritize the enabling factors influencing IoT adoption in manufacturing organizations from a perspective of supply chain sustainability. Thus, this paper makes potential major contributions to manufacturing companies in an emerging economy that are planning to invest in IoT systems, in terms of providing a holistic view of key enabling factors and their relative importance to IoT adoption with the consideration of sustainability. Mixed method research integrating both quantitative and qualitative data and associated analyses for evaluating IoT adoption in a context of supply chain sustainability was performed. The overall methodology adopted consists of three stages: (1) identifying the enabling factors for IoT adoption with a sustainability focus from the selected existing literature, (2) prioritizing these identified enabling factors using the grey relational analysis (GRA) method, and (3) verifying research findings using qualitative data from interviews of industry executives in Thai manufacturing organizations. In this case, supply chain sustainability was incorporated through a comprehensive review of enabling factors and associated scale items that relate to the successful adoption of IoT. For example, human capital (HC) as one of the key enabling factors was evaluated through four measures, including "employee's safety in human-machine interaction", that directly relate to the social dimension of sustainability. Similarly, all the elements (scales items) that are used to measure each enabling factor cover economic benefits, environmental conditions, and social needs.

The remainder of this paper is organized as follows. Section 2 is devoted to the critical review of related literature on IoT adoption in managing supply chain, IoT adoption, and sustainability, and enabling factors for IoT adoption for sustainability in SCM. Section 3 is the description of the research design. Section 4 illustrates the results of both quantitative and qualitative analyses, emphasizing supply chain sustainability. Research findings and discussions are presented in Section 5. Lastly, Section 6 proposes research implications and conclusions.

\section{Literature Review}

\subsection{IoT Adoption in Managing Supply Chain}

There are several studies reported in the literature on the broader subject of IoT, including the latest IoT systems, IoT applications and adoption, and IoT adoption sustainability. This section presents a critical review of the relevant and contemporary literature on those 
key areas of IoT. Boyes et al. [27] developed a definition of the Industrial Internet of Things (IIoT) and examined related partial IoT taxonomies. They presented a framework for IIoT analysis which can be used to compute and describe IIoT devices while reviewing different system architecture. Ammar et al. [28] provided an overview of a current state-of-the-art IoT platform and identified the trends of different IoT platforms and security issues of the IoT framework. Li et al. [29] presented a survey of the latest requirements of the IoT with associated communication technology and a survey of emerging technologies and enabling applications with a focus on 5G IoT. Kassab and Darabkh [30] presented an overview of IoT evolution, its stack's protocols, technologies, applications, and the research challenges facing the implementation of this technology. A systematic framework to investigate the impacts of IIoT on established manufacturing business models is provided [31]. This study also reported the value of production and process optimization offered by IIoT by focusing on the customer importance in the decision-making process that can promote positive changes to the business models.

IoT is increasingly adopted in various production systems and supply chain processes and also in a wide variety of applications. These works of literature are some research studies of different IoT adoptions. A summary of IoT applications and key enabling technologies and contributing to the latest internet technologies that summarize current things in industries is presented by [32]. Arnold and Voigt [33] conducted an investigation for Industrial IoT adoption by manufacturing organizations. They reported the various ecosystem dimensions of the business, such as customers, suppliers, external organizations, and research institutes. Yerra and Pilla [34] utilized IoT technologies in an automotive body shop to optimize the material flow, reduce manufacturing cycle time, and reduce operational costs. They used computer simulations to compare the production times of the existing and the proposed IIoT-based systems. Ben-Daya et al. [17] provided the latest developments of the IoT adoption to various supply chain processes. They explored IoT in a supply chain management (SCM) context, provided an IoT definition in the SCM context, and presented its key enabling technologies.

Benefits of IoT-based systems in managing supply chains include information continuity and traceability, information accessibility, the link between information flow and material flow, and a decrease in the code of conduct violation and fraud [35]. Tu [36] identified the key factors of IoT adoption in logistics and supply chain management using a mixed method research approach. The results showed that potential benefits, perceived costs, and external pressure are significant factors of IoT adoption, and technology trust is an insignificant factor. Mostafa et al. [37] proposed a framework to implement the IoT system in warehouse management, which can help in improving real-time warehouse visibility, increasing speed and operations efficiency, and preventing inventory shortage and counterfeiting. Tejesh and Roy [38] developed an IoT-based inventory management system and open source hardware. This system can be utilized for monitoring and tracking all the information about goods such as the location of an item in the storage area. Hu et al. [39] presented IoT implementation for the online retailer's decisions. The retailers can access the different types of customer information and analyze the current market requirements through IoT systems and from other disruptive technologies such as Big Data and Cloud computing. Tahiliani and Digalwar [40] reviewed the most important research carried out on the emerging issue of energy efficiency in IoT systems. The major challenges of energy efficiency in green IoT-based systems have been presented. Gapchup et al. [41] presented various topics of using IoT technologies in healthcare systems, including IoT healthcare networks, advantages of IoT in a healthcare organization, applications of IoT in the healthcare industry, and challenges of IoT in the healthcare industry. Ghosh [42] proposed a system with the use of many sensors and other emerging IoT technologies in the agriculture industry to monitor the current soil conditions and the need for fertilizer or water giving the local farmer a comfortable zone to cultivate the crop and leading to reduced crop loss, reduced overall cultivating cost, and increased profit. 


\subsection{IoT Adoption and Sustainability}

Adopting Industry 4.0 (I4.0) or the Internet of Things (IoT) is recognized as a key driver for enhancing sustainability in production systems or various supply chain functions. Many research studies have surveyed and covered different aspects of sustainability in I4.0 or IoT adoption. Felsberger and Reiner [43] presented the systematic literature review and the focus group discussions contributing to the evaluation of manufacturing sustainability and supply chain process improvement for Industrial 4.0 technology adoption. Their work filled potential gaps in the literature concerning dependencies between the evaluations of the economic, environmental, and social sustainability based on adopting various emerging technologies. Jamwal et al. [44] systematically reviewed the literature to identify the current research progress and future research potential of Industry 4.0 technologies to achieve manufacturing sustainability. Industry 4.0 implementations support the triple bottom line (TBL) of sustainability through productivity and product quality improvement (economic benefit), continuous monitoring of energy consumption (environmental impact), and safer working environment, less intense workload, and job enrichment (social needs) and the improvement in economic sustainability directly affects environmental sustainability by improving the efficiency of resource utilization and social sustainability by higher taxes [21]. Waibel et al. [3] discussed the effects of smart manufacturing systems in a sustainable setting, in which they evaluated each sustainability aspect (economic, social, environmental, and technical) in terms of efficiency of resources. Vass et al. [45] revealed that various IoT-based systems provide additional capacities in data auto-capture, visibility, intelligence, and information sharing for integration of retail supply chains, in turn enhancing supply chain performances in operating cost, quality, delivery, and flexibility to improve company economic, social, and environmental sustainability. Narula et al. [46] reviewed an expert-based analysis to evaluate the importance of Industry 4.0 technologies adoption on the global standard of sustainability. The findings indicated that $85 \%$ of environmental, $65 \%$ of economic, and $50 \%$ of social standards are influenced by Industry 4.0 . The most common sustainability benefits of I4.0 technologies and green processes are energy saving, emission reduction, resource optimization, cost reduction, productivity and efficiency, higher economic performance, human resource development, social welfare, and workplace safety [47].

However, some studies focus on the impact of I4.0 or IoT adoption only one or two sustainability dimensions. For example, some studies paid a lot of attention to economic sustainability. According to a survey from Brozzi et al. [48], it can conclude that industries are now focusing more on economic sustainability as compared to social and environmental sustainability. De Sousa Jabbour et al. [15] found that Industry 4.0 projects help to reduce operational costs, improve the circular economy and market share of products, and create a new business model which enhances economic sustainability in industries. Varela et al. [49] discovered that the Industry 4.0 revolution will be more favorable for economic sustainability by reducing manpower, energy consumption, and production lead time and improving productivity in manufacturing processes. It was found that business model innovation and production efficiency are the major functions for industries to maintain economic sustainability in Industry 4.0 [50]. With regards to environmental sustainability, Adebiyi and Cruz [51] presented a research study relating to analyzing the current situation of green sustainability in business technologies, developing sustainability strategies to business processes for emerging technologies, and creating a strategic plan for the green and sustainable development of emerging technologies. Some research papers reviewed negative impacts on social sustainability. Frank et al. [52] concluded that more automation in the industry will result in less manual labor and introducing a new machine in the manufacturing system will affect certain jobs previously done by workers. These conditions result in increased unemployment and thereby directly and adversely impact social sustainability. 


\subsection{Enabling Factors for IoT Adoption for Sustainability in SCM}

Critical success factors or enabling factors are conditions or variables which are crucial for an organization or project to achieve effectiveness, efficiency, and viability. In this research, an analysis of these factors in conjunction with the sustainability of IoT implementation was conducted. Tripathi and Pandit [53] reviewed the positive and negative factors of IoT adoption with help of the system dynamics model. The model provided a clear picture of technical, personal, and organizational factors of IoT adoption. Their study is a major contribution towards understanding the factors influencing the adoption of technologies or innovations such as IoT in businesses. Nord et al. [54] developed a theoretical framework and conceptual model related to IoT and highlighted the factors that influence IoT adoption by organizations. Roy et al. [55] validated the fundamental factors for the easy adoption of IoT-based innovations. They performed the study in four different stages of literature review, survey, interviews with experts, and a usability test to develop a model for IoT adoption by the urban poor communities. Haddud et al. [56] assessed the potential benefits and challenges of IoT adoption for individual organizations and complete supply chains by conducting an online survey of academicians across six continents. Gotmare et al. [22] identified the critical barriers to IoT adoption in the Indian manufacturing sector. Based on the AHP analysis in this study, the most significant barriers for IoT adoption are lack of top management vision, high initial investment cost, and risk involved in transitioning to a new business model. In general, AHP is used to systematically integrate various judgments from separate assessors to set the weights as a basis of selection, evaluation, and allocation of different criteria of MCDM problem [57] such as supplier selection [58,59]. However, AHP does not apply to ambiguous and/or grey relationships among the main factors under consideration [58]. In this context, grey theory accounts for qualitative judgments and can be successfully incorporated into any decision-making process to improve the accuracy of judgments [60].

Most of the previous studies presented fundamental concepts of Industry 4.0 (I4.0) and IoT technologies and various I4.0 and IoT applications in different industries. Many of them reviewed I4.0 and IoT adoption and its impact on economic, environmental, and social sustainability. Moreover, some of the research studies identified critical success factors, barriers, and challenges for the adoption of I4.0 and IoT systems. Based on the current literature, the studies of enabling factors of IoT adoption with supply chain sustainability are quite limited. Thus, this research study addresses the major gap in research of enabling factors for IoT adoption with a sustainability perspective. A summary of literature reviews and their study focuses is presented in Table 1.

Table 1. Summary of literature reviews and their study focuses.

\begin{tabular}{|c|c|c|c|c|c|}
\hline \multicolumn{4}{|c|}{ Study Focuses } & \multirow[b]{2}{*}{ Key Contributions } & \multirow[b]{2}{*}{ Author(s) Reference } \\
\hline $\begin{array}{c}\text { I4.0/IoT } \\
\text { Adoption }\end{array}$ & $\begin{array}{c}\text { I4.0/IoT } \\
\text { Adoption and } \\
\text { Sustainability }\end{array}$ & $\begin{array}{c}\text { I4.0/IoT } \\
\text { Adoption and } \\
\text { Enabling } \\
\text { Factors }\end{array}$ & $\begin{array}{l}\text { I4.0/IoT Adoption } \\
\text { and Enabling } \\
\text { Factors and } \\
\text { Sustainability }\end{array}$ & & \\
\hline$\checkmark$ & & & & $\begin{array}{ll}\text { - } & \text { IoT definition and taxonomies. } \\
\text { - } & \text { IoT platform and IoT evolution. } \\
\text { - IoT applications and key } \\
\text { enabling technologies. } \\
\text { IoT adoption in manufacturing } \\
\text { organizations and various } \\
\text { supply chain processes such as } \\
\text { warehouse and inventory } \\
\text { management. } \\
\text { IoT applications in retail, } \\
\text { healthcare, and agricultural } \\
\text { industries. }\end{array}$ & $\begin{array}{l}\text { Boyes et al. [27], } \\
\text { Ammar et al. [28], } \\
\text { Kassab and Darabkh [30], } \\
\text { Da Xu et al. [32], } \\
\text { Arnold and Voigt [33], } \\
\text { Ben-Daya et al. [17], } \\
\text { Mostafa et al. [37], } \\
\text { Tejesh and Roy [38], } \\
\text { Hu et al. [39], } \\
\text { Gapchup et al. [41], } \\
\text { Ghosh [42] }\end{array}$ \\
\hline
\end{tabular}


Table 1. Cont.

\begin{tabular}{|c|c|c|c|c|c|}
\hline \multicolumn{4}{|c|}{ Study Focuses } & \multirow[b]{2}{*}{ Key Contributions } & \multirow[b]{2}{*}{ Author(s) Reference } \\
\hline $\begin{array}{c}\text { I4.0/IoT } \\
\text { Adoption }\end{array}$ & $\begin{array}{c}\text { I4.0/IoT } \\
\text { Adoption and } \\
\text { Sustainability }\end{array}$ & $\begin{array}{l}\text { I4.0/IoT } \\
\text { Adoption and } \\
\text { Enabling } \\
\text { Factors }\end{array}$ & $\begin{array}{l}\text { I4.0/IoT Adoption } \\
\text { and Enabling } \\
\text { Factors and } \\
\text { Sustainability }\end{array}$ & & \\
\hline & $\checkmark$ & & & $\begin{array}{l}\text { I4.0 and IoT adoption and the } \\
\text { impact or improvement in } \\
\text { economic, social, and } \\
\text { environmental sustainability. }\end{array}$ & $\begin{array}{l}\text { Felsberger and Reiner [43], } \\
\text { Jamwal et al. [44], } \\
\text { Braccini and Margherita [21], } \\
\text { Vass et al. [45], } \\
\text { Narula et al. [46], } \\
\text { Vrchota et al. [47], } \\
\text { De Sousa Jabbour et al. [15], } \\
\text { Varela et al. [49], } \\
\text { Frank et al. [52] }\end{array}$ \\
\hline & & $\checkmark$ & & $\begin{array}{l}\text { - IoT adoption and its critical } \\
\text { success factors, enabling factors, } \\
\text { or critical barriers. } \\
\text { IoT adoption and its potential } \\
\text { benefits and challenges. }\end{array}$ & $\begin{array}{l}\text { Tripathi and Pandit [53], } \\
\text { Nord et al. [54], } \\
\text { Roy et al. [55], } \\
\text { Haddud et al. [56], } \\
\text { Gotmare et al. [22] }\end{array}$ \\
\hline & & & $\checkmark$ & $\begin{array}{l}\text { Enabling factors of IoT adoption } \\
\text { for sustainability in supply } \\
\text { chain management. }\end{array}$ & The authors \\
\hline
\end{tabular}

\section{Research Design}

In this research, a mixed method research approach using qualitative and quantitative data and associated analyses was adopted through three stages. The three stages were (1) identification of enabling factors and performance measures of IoT adoption considering supply chain sustainability based on the existing literature, (2) empirical prioritization of these enabling factors by the use of inputs from industry experts of manufacturing in Thailand, and (3) verification of the empirical study using inputs from interviews of industry executives in different manufacturing organizations in Thailand.

The first stage was aimed at determining major enabling factors and performance measures of IoT success in the context of sustainability in supply chain management using the contemporary literature. The second stage involved prioritizing each enabling factor, considering all performance measures, using grey relational analysis (GRA). Taking into consideration some limitations of AHP outlined above and the connection of qualitative judgments with the grey theory, grey relational analysis (GRA) is a well-established and accepted approach of multi-criteria decision making (MCDM) that combines both qualitative and quantitative data [61]. Therefore, this research adopted GRA over AHP approach, particularly accommodating the ambiguous relationships among enabling factors and performance rankings. For the GRA approach, performance measures were used to rate each enabling factor on a scale of 1 to 10 where 1 is the lowest rank of importance and 10 is the highest rank of importance. These rating decisions were based on the input from industry experts in Thailand. In the third stage, interviews with industry executives were conducted to describe and confirm/validate the empirical findings from the first two stages. These interviews consisted of six industry practitioners/executives of Thai manufacturing companies. These three stages are explained in detail next.

\subsection{Stage 1: Identification of Enabling Factors and Performance Measures of IoT Adoption Sustainability}

Based on evidence from the literature, many researchers have focused on factors or barriers to RFID, IoT, or Industry 4.0 adoption but few research works have been done on analyzing enabling factors and performance measures of IoT adoption with consideration of supply chain sustainability. The keywords for the literature review of key performance measures include process stability, flexibility, reliability, visibility, connectivity, customer demand, and information security and privacy. Each of these keywords was associated 
with IoT adoption and sustainability for better search results. Search boundaries included key databases such as EBSCO, Google Scholar, Emerald, Science Direct, Taylor and Francis, and Scopus. The period covered was up to 2021. Exclusion criteria included articles with very limited exposure to those performance measures and no connection to IoT adoption and sustainability. Inclusion criteria included an article with at least 5 or more performance measures covered.

The reviewed literature provided a range of possible performance measures that have been related to the success of the IoT adoption with supply chain sustainability. Table 2 shows the list of selected performance measures determined from the literature review described above. This study selected the four performance measures that have been cited most and referred to them as customer demand, process stability, supply chain connectivity, and product/process flexibility.

Table 2. List of performance measures for adopting IoT with supply chain sustainability.

\begin{tabular}{|c|c|c|c|c|c|c|c|}
\hline & $\begin{array}{l}\text { Process } \\
\text { Stability }\end{array}$ & $\begin{array}{l}\text { Product/Process } \\
\text { Flexibility }\end{array}$ & Visibility & Reliability & $\begin{array}{l}\text { Customer } \\
\text { Demand }\end{array}$ & $\begin{array}{l}\text { Supply Chain } \\
\text { Connectivity }\end{array}$ & Privacy \\
\hline Ben-Daya et al. [17] & $\checkmark$ & $\checkmark$ & & $\checkmark$ & $\checkmark$ & $\checkmark$ & \\
\hline Bogataj et al. [62] & $\checkmark$ & $\checkmark$ & $\checkmark$ & & & $\checkmark$ & $\checkmark$ \\
\hline Haddud et al. [56] & $\checkmark$ & $\checkmark$ & & $\checkmark$ & $\checkmark$ & $\checkmark$ & \\
\hline Dweekat et al. [63] & $\checkmark$ & $\checkmark$ & & & $\checkmark$ & $\checkmark$ & $\checkmark$ \\
\hline Del Giudice [64] & $\checkmark$ & $\checkmark$ & & & & $\checkmark$ & \\
\hline Kache and Seuring [65] & $\checkmark$ & $\checkmark$ & $\checkmark$ & & $\checkmark$ & $\checkmark$ & \\
\hline Yu et al. [66] & $\checkmark$ & & & $\checkmark$ & $\checkmark$ & $\checkmark$ & \\
\hline Rymaszewska et al. [67] & $\checkmark$ & $\checkmark$ & & $\checkmark$ & & $\checkmark$ & $\checkmark$ \\
\hline Mishra et al. [68] & $\checkmark$ & $\checkmark$ & $\checkmark$ & & $\checkmark$ & $\checkmark$ & \\
\hline Parry et al. [69] & $\checkmark$ & $\checkmark$ & & & & $\checkmark$ & $\checkmark$ \\
\hline Strozzi et al. [70] & $\checkmark$ & $\checkmark$ & & $\checkmark$ & $\checkmark$ & $\checkmark$ & \\
\hline Tu et al. [71] & $\checkmark$ & $\checkmark$ & $\checkmark$ & & & $\checkmark$ & \\
\hline Yan [72] & $\checkmark$ & $\checkmark$ & & $\checkmark$ & $\checkmark$ & $\checkmark$ & \\
\hline Wu et al. [6] & $\checkmark$ & $\checkmark$ & $\checkmark$ & & & $\checkmark$ & $\checkmark$ \\
\hline Weinberg et al. [73] & $\checkmark$ & $\checkmark$ & & $\checkmark$ & $\checkmark$ & & $\checkmark$ \\
\hline Strange and Zucchella [74] & $\checkmark$ & & $\checkmark$ & & $\checkmark$ & $\checkmark$ & \\
\hline Total & 16 & 14 & 6 & 7 & 10 & 15 & 6 \\
\hline
\end{tabular}

For the enabling factor selection process, the literature was reviewed by the keywords, including enabling factor, IoT adoption, and supply chain sustainability, using the search boundaries described above and the period covered up to 2021. Exclusion criteria included articles with very limited relation to IoT adoption, enabling factors, and sustainability. Inclusion criteria included articles with a conceptual framework of IoT adoption and scales for measuring at least one enabling factor. Five enabling factors, based on the literature review, were identified for success in IoT adoption with the supply chain sustainability, including system integration (SI), IoT infrastructure (IoTI), supply chain responsiveness (SCR), human capital (HC), and organizational climate and culture (OCC). The enabling factors refer to the ability of an entity to realize the IoT adoption in managing the supply chain sustainability. To ensure accuracy and relevance of the five enabling factors, they were confirmed by evaluating them using secondary data (i.e., annual reports of companies, business magazines, technical reports, and white papers) to understand their association with industry examples and how they were applied. Table 3 shows the selected enabling factors, associated scale items, and references supporting these enabling factors. 
Table 3. Enabling factors, scale items, and references that relate to performance measures for implementing IoT with supply chain sustainability.

\begin{tabular}{|c|c|c|}
\hline Enabling Factors & Scale Items & References \\
\hline \multirow{4}{*}{ System Integration (SI) } & 1. Interoperability interfaces & \multirow{4}{*}{$\begin{array}{l}\text { Tripathi and Pandit [53]; Noura et al. [75]; } \\
\text { Yacob et al. [76]; Siddiqui et al. [77]; } \\
\text { Trzaskoma [78] }\end{array}$} \\
\hline & 2. Supplier flexibility and capability & \\
\hline & $\begin{array}{l}\text { 3. Information and operational technologies steadily } \\
\text { merging }\end{array}$ & \\
\hline & 4. Compatibility among technology systems & \\
\hline \multirow{4}{*}{ IoT Infrastructure (IoTI) } & 1. Data flows with privacy and security & \multirow{4}{*}{$\begin{array}{l}\text { Yacob et al. [76]; Olushola [79]; } \\
\text { Gotmare et al. [22]; Tripathi and } \\
\text { Pandit [53]; Siddiqui et al. [77] }\end{array}$} \\
\hline & 2. Internet and technological infrastructure & \\
\hline & 3. Government regulatory support to IoT adoption & \\
\hline & 4. Right vendor to provide right IoT infrastructure & \\
\hline \multirow{2}{*}{$\begin{array}{c}\text { Supply Chain } \\
\text { Responsiveness (SCR) }\end{array}$} & $\begin{array}{l}\text { 1. Flexible adaption of technologies to changing } \\
\text { requirements }\end{array}$ & \multirow{2}{*}{ Lak and Rezaeenour [80]; Kamble et al. [7] } \\
\hline & 2. Capability of real-time response & \\
\hline \multirow{4}{*}{ Human Capital (HC) } & 1. Skilled and expert professionals & \multirow{4}{*}{$\begin{array}{l}\text { Tripathi and Pandit [53]; Gotmare et al. [22]; } \\
\text { Kagermann et al. [81]; Martins et al. [82] }\end{array}$} \\
\hline & $\begin{array}{l}\text { 2. Employees with high degree of technological } \\
\text { readiness }\end{array}$ & \\
\hline & 3. Training programs for employees & \\
\hline & 4. Employee's safety in human-machine interaction & \\
\hline \multirow{3}{*}{$\begin{array}{l}\text { Organizational Climate and } \\
\text { Culture (OCC) }\end{array}$} & 1. Clear understanding about IoT goals and benefits & \multirow{3}{*}{$\begin{array}{l}\text { Gotmare et al. [22]; Marques et al. [83]; Lak } \\
\text { and Rezaeenour [80]; Trzaskoma [78] }\end{array}$} \\
\hline & 2. Willingness to commit to technological investment & \\
\hline & 3. Decentralized and optimized decision making & \\
\hline
\end{tabular}

Therefore, it is considered that these five selected enabling factors and seventeen associated scale items are relevant to the IoT implementation for sustainability in the context of supply chain management. System integration (SI), such as interoperability interfaces, supplier flexibility, and capability, and compatibility among technology systems positively affects IoT adoption. These aspects of SI bring the potential of quicker response to customer needs, lower operating and maintenance costs, and higher business productivity, resulting in enhancing the economic sustainability of IoT adoption. IoT infrastructure (IoTI), in terms of data security and privacy, government regulatory support to IoT adoption, and the right vendor for the right IoT infrastructure, significantly impacts IoT systems. The aspects of IoTI can provide increased economic sustainability of IoT adoption through the improvement concerning technology precision and process efficiency and the reduction of operating, maintenance, and inventory management costs.

Supply chain responsiveness (SCR), including the flexible adaption of technologies to changing requirements and capability of real-time response, helps production systems and supply chain processes in more easily finding problems, accurately and timely making decisions, significantly reducing defective parts and machine downtime, better utilizing assets, satisfying new demands, and ultimately increasing return on investment of the organizations. Human capital (HC), consisting of skilled and expert professionals, employees with a high degree of technological readiness, and training programs for employees, has the high potential to bring economic sustainability to IoT adoption, in terms of increased business productivity, process efficiency, and efficient asset utilization and decreased operating and maintenance costs to the organizations. However, employee safety in human-machine interaction tends to benefit the social sustainability of IoT adoption due to a safer workplace environment, better working conditions, accident reduction, and less intense workload. Organizational climate and culture (OCC), based on a clear understanding of IoT goals 
and benefits, willingness to commit to technological investment, and decentralized and optimized decision-making mainly provide economic sustainability to IoT investment through the improvement of efficient asset and resource utilization, accurate decisionmaking processes, quick problem solving, and the increase of return on investment. Due to these five enabling factors and their associated benefits, they present visible evidence that IoT implementation significantly affects supply chain sustainability, highly in economic sustainability and rarely in social sustainability.

Based on the four performance measures and five enabling factors selected from the literature search identified above, the hierarchical model of performance measures and enabling factors is shown in Figure 1.

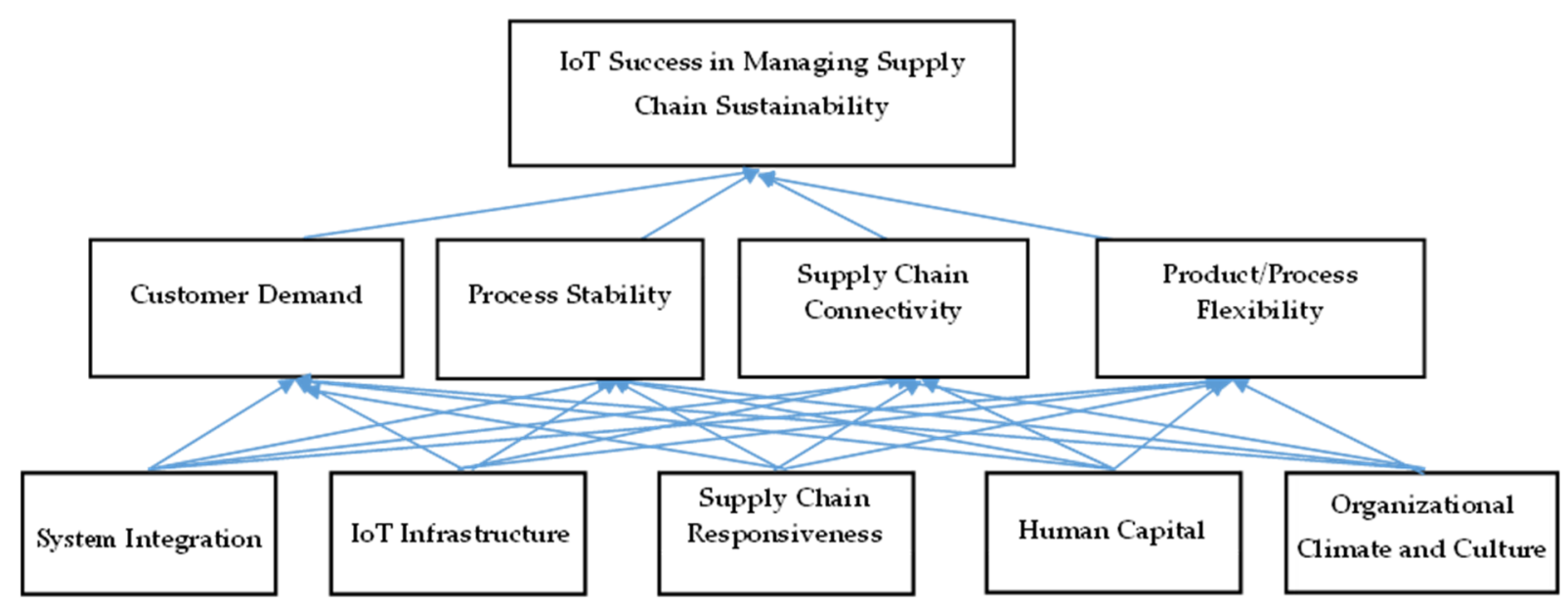

Figure 1. Hierarchical model of enabling factors and performance measures for measuring IoT success considering supply chain sustainability.

\subsection{Stage 2: Prioritization of Each Enabling Factor Using GRA}

The GRA procedure was adopted to rank enabling factors based on quantitative data from a range of evaluators [84]. Five steps of GRA procedure are explained in detail in the Section 4. In this stage, input was sought from industry experts from sixteen different companies in Thailand where these companies have adopted some IoT technologies, platforms, and/or solutions in managing their supply chain sustainability. Table 4 shows profiles of the sixteen industry experts who contributed to prioritizing enabling factors.

Table 4. Details of industry experts that contributed to GRA.

\begin{tabular}{|c|c|c|c|}
\hline Position & No. & Background and Experiences & Company's Details \\
\hline \multirow{7}{*}{$\begin{array}{l}\text { Board } \\
\text { Member }\end{array}$} & 1 & $\begin{array}{l}\text { Engineering degree, } 27 \text { years of } \\
\text { experience }\end{array}$ & $\begin{array}{l}\text { The automotive industry, } 1850 \text { employees, } 3 \text { plants in } 2 \text { countries } \\
\text { in Asia }\end{array}$ \\
\hline & 2 & MBA, 30 years of experience & The automotive industry, 460 employees, 1 plant in Thailand \\
\hline & 3 & MBA, 27 years of experience & $\begin{array}{l}\text { The automotive industry, } 750 \text { employees, } \\
2 \text { plants in different locations in Thailand }\end{array}$ \\
\hline & 4 & $\begin{array}{l}\text { Engineering degree, } 23 \text { years of } \\
\text { experience }\end{array}$ & The automotive industry, 240 employees, 1 plant in Thailand \\
\hline & 5 & MBA, 17 years of experience & Food and beverage industry, 320 employees, 1 plant in Thailand \\
\hline & 6 & MBA, 32 years of experience & $\begin{array}{l}\text { Food and beverage industry, } 540 \text { employees, } 3 \text { plants in different } \\
\text { locations in Thailand }\end{array}$ \\
\hline & 7 & MSc, 24 years of experience & Food and beverage industry, 250 employees, 1 plant in Thailand \\
\hline
\end{tabular}


Table 4. Cont.

\begin{tabular}{|c|c|c|c|}
\hline Position & No. & Background and Experiences & Company's Details \\
\hline \multirow{7}{*}{$\begin{array}{l}\text { Managing } \\
\text { Director }\end{array}$} & 8 & MBA, 29 years of experience & $\begin{array}{l}\text { Electronics parts and components industry, } 480 \text { employees, } 2 \text { plants } \\
\text { in different locations in Thailand }\end{array}$ \\
\hline & 9 & $\begin{array}{l}\text { Engineering degree, } 25 \text { years of } \\
\text { experience }\end{array}$ & $\begin{array}{l}\text { Electronics parts and components industry, } 180 \text { employees, } 1 \text { plant } \\
\text { in Thailand }\end{array}$ \\
\hline & 10 & $\begin{array}{l}\text { Engineering degree, } 22 \text { years of } \\
\text { experience }\end{array}$ & $\begin{array}{l}\text { Electronics parts and components industry, } 470 \text { employees, } 2 \text { plants } \\
\text { in different locations in Thailand }\end{array}$ \\
\hline & 11 & $\begin{array}{l}\text { Engineering degree, } 30 \text { years of } \\
\text { experience }\end{array}$ & $\begin{array}{l}\text { Retail industry, } 1750 \text { employees, } 4 \text { distribution centers in } 4 \text { different } \\
\text { locations in Thailand }\end{array}$ \\
\hline & 12 & MBA, 27 years of experience & $\begin{array}{l}\text { Retail industry, } 2500 \text { employees, } 3 \text { distribution centers in } 3 \text { different } \\
\text { locations in Thailand }\end{array}$ \\
\hline & 13 & MBA, 30 years of experience & $\begin{array}{l}\text { Retail industry, } 1250 \text { employees, } 2 \text { distribution centers in } 2 \text { different } \\
\text { locations in Thailand }\end{array}$ \\
\hline & 14 & $\begin{array}{l}\text { Engineering degree, } 32 \text { years of } \\
\text { experience }\end{array}$ & $\begin{array}{l}\text { Retail industry, } 2150 \text { employees, } 4 \text { distribution centers in } 4 \text { different } \\
\text { locations in Thailand }\end{array}$ \\
\hline \multirow{2}{*}{$\begin{array}{l}\text { Regional } \\
\text { Director }\end{array}$} & 15 & MBA, 35 years of experience & $\begin{array}{l}\text { Furniture industry, } 780 \text { employees, } 4 \text { plants in } 4 \text { different countries } \\
\text { in Asia }\end{array}$ \\
\hline & 16 & $\begin{array}{l}\text { Engineering degree, } 32 \text { years of } \\
\text { experience }\end{array}$ & $\begin{array}{l}\text { Furniture industry, } 1200 \text { employees, } 3 \text { plants in } 3 \text { different locations } \\
\text { ( } 2 \text { in Asia and } 1 \text { in Europe) }\end{array}$ \\
\hline
\end{tabular}

As shown in Table 4, all but one company (No. 9) are large in size with more than 200 employees. This indicates that IoT implementation is mainly in large companies in Thailand, possibly due to the large capital investment required.

\subsection{Stage 3: Semi-Structured Interviews of Industry Executives}

Semi-structured interviews were carried out with six executives with knowledge and experience of adopting IoT in managing a sustainable supply chain. Each interview of about 90-120 min was conducted through an online Zoom meeting and was also videorecorded. The recording was then transcribed on the same day of the online meeting. The primary objective of the interviews was to provide a richer context to some of the findings from the empirical analysis in the earlier stages of the research. In particular, the interviews sought to understand why the top ranked enabling factors were regarded so highly. Interviews were structured around the following questions: (1) what are the key IoT systems or devices adopted in your company? (2) In your opinion, what are the most important enabling factors (among these five selected enabling factors) for IoT success with supply chain sustainability? (3) What are the key benefits obtained from your IoT systems or devices? and (4) What are your suggestions or recommendations for IoT success? The six interviewees consisted of assistant general manager of supply chain management for an automotive manufacturing company with 12 years of industry experience (Interviewee T); vice president of operations for a semiconductor manufacturing company with 24 years of industry experience (Interviewee W); third-party logistics compliance manager for a consumer product manufacturing company with 12 years of industry experience (Interviewee M); third-party logistics service provider, regional manager with 18 years of industry experience (Interviewee D); logistics and supply chain director for electronic goods/appliances manufacturing company with 20 years of industry experience (Interviewee $\mathrm{H}$ ); and operations director, the distribution center of a food/beverage manufacturing company with 28 years of industry experience (Interviewee B).

\section{Results and Analyses}

This section presents the empirical findings from the GRA analysis and the semistructured interviews carried out with the inputs from industry experts/executives. 


\subsection{GRA Analysis and Results}

The steps of the GRA approach and accompanying results are outlined below, including a flow chart (Figure 2) summarizing the process steps.
Step 1: Select the criteria for evaluating the enabling factors of IoT implementation with supply chain sustainability.

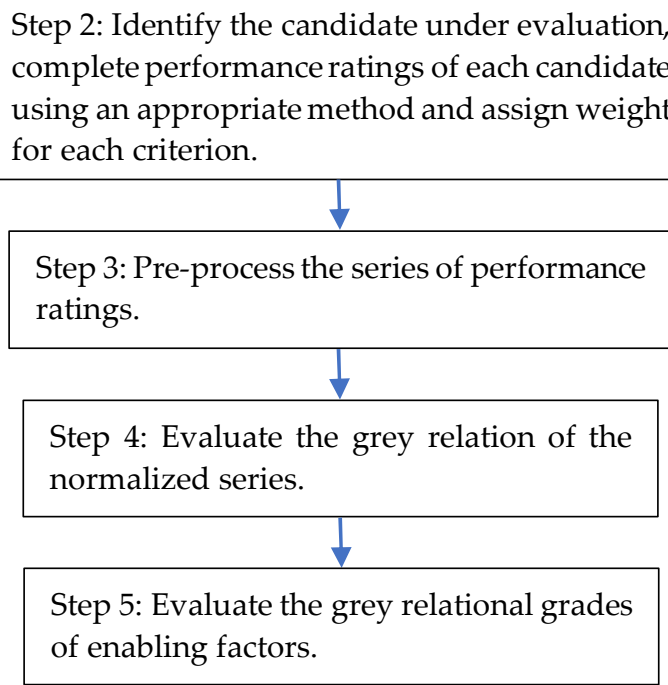

Figure 2. Five steps of GRA analysis.

Step 1: Select the criteria for evaluating the enabling factors of IoT implementation with supply chain sustainability.

The criteria are the performance measures identified in the previous section, including (i) customer demand (C1), (ii) process stability (C2), (iii) supply chain connectivity (C3), and (iv) product/process flexibility (C4). For all these four criteria, the larger the better.

Step 2: Identify the candidate under evaluation, complete performance ratings of each candidate using an appropriate method, and assign a weight for each criterion.

The candidates for evaluation are the enabling factors of IoT implementation with supply chain sustainability, in this study, assuming that each performance measure has the same weight (i.e., 25 percent each for four performance measures). The performance ratings were evaluated using inputs from sixteen industry experts. This research study did not use a survey for data collection. Therefore, the number of the selected sample (industry expert) is not a major concern. However, this study particularly focused on interviews of a specific group of experts in IoT adoption especially in an early stage of technology diffusion $[85,86]$.

To rate each performance measure, relative to each enabling factor, each industry expert was asked to rank each performance measure using a score of 1 to 10 where 10 is $100 \%$ achievement of the selected performance measure relative to each enabling factor. Once all performance measures were ranked against each enabling factor, the average of sixteen industry expert ratings was considered as the overall rating (achievement) of each performance measure. The performance ratings of enabling factors and weights of performance measures are shown in Table 5. For example, a rating of 9.38 for customer demand against system integration means that customer demand is around $94 \%$ achieved, with respect to system integration. In other words, system integration enables the achievement of $94 \%$ of customer demand through IoT implementation in the context of supply chain sustainability. 
Table 5. Performance ratings of each enabling factor by industry experts.

\begin{tabular}{lcccc}
\hline \multirow{2}{*}{$\begin{array}{c}\text { Dimension } \\
\text { (Enabling Factor) }\end{array}$} & \multicolumn{4}{c}{ Level of: } \\
\cline { 2 - 5 } & $\begin{array}{c}\text { Customer } \\
\text { Demand (C1) }\end{array}$ & $\begin{array}{c}\text { Process Stability } \\
\text { (C2) }\end{array}$ & $\begin{array}{c}\text { Supply Chain } \\
\text { Connectivity (C3) }\end{array}$ & $\begin{array}{c}\text { Product/Process } \\
\text { Flexibility (C4) }\end{array}$ \\
\hline System Integration $\left(X_{1}\right)$ & 9.38 & 7.88 & 9.00 & 8.50 \\
\hline IoT Infrastructure $\left(X_{2}\right)$ & 8.88 & 8.31 & 9.00 & 8.38 \\
\hline Supply Chain Responsiveness $\left(X_{3}\right)$ & 8.50 & 7.75 & 7.50 & 7.94 \\
\hline Human Capital $\left(X_{4}\right)$ & 7.88 & 7.44 & 8.00 & 8.00 \\
\hline Organizational Climate and Culture $\left(X_{5}\right)$ & 7.81 & 7.31 & 7.94 & 8.31 \\
\hline Weight $(w)$ & 0.25 & 0.25 & 0.25 & 0.25 \\
\hline
\end{tabular}

As shown in Table 5, ratings of each performance measure with respect to each enabling factor are in the range of $73 \%$ to $94 \%$, suggesting a very high level of IoT success with supply chain sustainability, from the perspective of experiences of the study participants.

Step 3: Pre-process the series of performance ratings in Table 5.

Since for all the criteria, the larger the better, the data series in Table 5 can be preprocessed using the following method (Equation (1)), according to the semantics of the $j$ th element of the series.

$$
x_{i}^{*}(j)=\frac{\left(x_{i}(j)-\min x_{i}(j)\right)}{\max x_{i}(j)-\min x_{i}(j)} \quad \text { for } i=1,2 \ldots \ldots N
$$

The resulting series of ratings of enabling factors represented by $X_{i}^{*}$, including $X_{0}$ for the series of weight after normalization, are shown in Table 6.

Table 6. Normalized series of performance ratings of each enabling factor.

\begin{tabular}{ccccc}
\hline & C1 & C2 & C3 & C4 \\
\hline$X_{1}^{*}$ & 1.00 & 0.56 & 1.00 & 1.00 \\
\hline$X_{2}^{*}$ & 0.68 & 1.00 & 1.00 & 0.78 \\
\hline$X_{3}^{*}$ & 0.44 & 0.44 & 0.00 & 0.00 \\
\hline$X_{4}^{*}$ & 0.04 & 0.13 & 0.33 & 0.11 \\
\hline$X_{5}^{*}$ & 0.00 & 0.00 & 0.29 & 0.67 \\
\hline$X_{0}$ & 1 & 1 & 1 & 1 \\
\hline
\end{tabular}

The enabling factor is considered as a candidate for evaluation, in terms of ranking the overall importance of each enabling factor when implementing IoT with sustainable development. Thus, the next step is to calculate the grade of the grey relational coefficient.

Step 4: Evaluate the grey relation of the normalized series.

Let the normalized series of $X_{i}=\left\{x_{i}(j)\right\}$ be denoted as $X_{i}^{*}=\left\{x_{i}^{*}(j)\right\}$. Thus, the grey relation of each element $\gamma_{0 i}^{*}(j)$ is calculated using the following equations:

$$
\gamma_{0 i}^{*}(j)=\frac{\Delta^{*} \min +\Delta^{*} \max }{\Delta_{0 i}^{*}(j)+\Delta^{*} \max }
$$

where

$$
\begin{aligned}
& \Delta_{0 i}^{*}(j)=\left|x_{0}^{*}(j)-x_{i}^{*}(j)\right| \\
& \Delta^{*} \max ^{2}=\max _{i} \max _{j} \Delta_{0 i}^{*}(j) \\
& \Delta^{*} \min =\min _{i} \min _{j} \Delta_{0 i}^{*}(j)
\end{aligned}
$$

The resulting grey relations of the data series or enabling factors are shown in Table 7. 
Table 7. Resulting grey relations of enabling factors and each criterion weight.

\begin{tabular}{ccccc}
\hline & $\mathbf{C 1}$ & $\mathbf{C 2}$ & $\mathbf{C 3}$ & $\mathbf{C 4}$ \\
\hline$\gamma_{1}^{*}(j)$ & 1.00 & 0.70 & 1.00 & 1.00 \\
\hline$\gamma_{2}^{*}(j)$ & 0.76 & 1.00 & 1.00 & 0.82 \\
\hline$\gamma_{3}^{*}(j)$ & 0.64 & 0.64 & 0.50 & 0.50 \\
\hline$\gamma_{4}^{*}(j)$ & 0.51 & 0.53 & 0.60 & 0.53 \\
\hline$\gamma_{5}^{*}(j)$ & 0.50 & 0.50 & 0.59 & 0.75 \\
\hline Weight $(w)$ & 0.25 & 0.25 & 0.25 & 0.25 \\
\hline
\end{tabular}

Step 5: Evaluate the grey relational grades of enabling factors.

Grey relational grades of series were evaluated using the grey relation of each element and weight of $j$ th performance measure by the following equation:

$$
\Gamma_{0 i}^{*}=\sum_{j=1}^{k} w_{j} \gamma_{0 i}^{*}(j)
$$

Grey relational grades of each enabling factor $\left(X_{i}, i=1, \ldots, 5\right)$ and individual ranking of importance are shown in Table 8.

Table 8. Grey relational grades of enabling factors.

\begin{tabular}{lcc}
\hline \multicolumn{1}{c}{ Enabling Factor } & $\boldsymbol{\Gamma}_{0 i}^{*}$ & Rank \\
\hline System Integration $\left(X_{1}\right)$ & 0.924 & 1 \\
\hline IoT Infrastructure $\left(X_{2}\right)$ & 0.894 & 2 \\
\hline Supply Chain Responsiveness $\left(X_{3}\right)$ & 0.570 & 4 \\
\hline Human Capital $\left(X_{4}\right)$ & 0.543 & 5 \\
\hline Organizational Climate and Culture $\left(X_{5}\right)$ & 0.584 & 3 \\
\hline
\end{tabular}

The GRA analysis shows that when considering all measures as a single performance set, system integration (0.924) is the most important factor, followed by IoT infrastructure (0.894), organizational climate and culture (0.584), supply chain responsiveness $(0.570)$, and lastly, human capital (0.543). It can be noted from the ranking of these enabling factors that system integration and IoT infrastructure have not only ranked the highest but also their importance is significantly higher $(>0.9)$ compared to those of other factors $(<0.6)$. This could be attributed to a very close relationship between system integration and IoT infrastructure. These enabling factors were further explored from the perspective of interdependencies using semi-structured interviews carried out at the third stage of this research study.

\subsection{Finding from the Interviews}

The key observations from the semi-structured interviews carried out at the third stage are presented in Table 9. Since these interviews were aimed at both validating the importance of enabling factors for IoT adoption and exploring interdependencies among factors, key observations are presented, focusing on those aspects. The interviewees were industry executives with extensive experience in their respective fields. Therefore, their comments were instrumental in providing a deeper context to the perception of enabling factors for IoT adoption with sustainability. 
Table 9. Key observations from semi-structured interviews.

\begin{tabular}{|c|c|}
\hline Enabling Factors & Observations from Interviews \\
\hline \multirow[t]{2}{*}{ System Integration } & $\begin{array}{l}\text { "IoT system improves more efficient predictive maintenance processes by introducing more system } \\
\text { integration, real-time data analysis, and intelligent decision-making. This can bring sustainable advantages } \\
\text { to the company by providing optimized strategic maintenance plan, reduced resource consumption, and } \\
\text { increased longer asset life." (Interviewee W) }\end{array}$ \\
\hline & $\begin{array}{l}\text { "By implementing IoT solutions in the supply chain, it allows better coordination of devices/platforms and } \\
\text { optimizes energy used by signaling when is cheaper to do energy intensive operations." (Interviewee D) }\end{array}$ \\
\hline \multirow{3}{*}{ IoT Infrastructure } & $\begin{array}{l}\text { "IoT systems, requiring a robust internet/technology infrastructure, can enhance communication and } \\
\text { decision-making capability among supply chain members and in turn creating a new business opportunity, } \\
\text { especially start-ups who provide service platform." (Interviewee W) }\end{array}$ \\
\hline & $\begin{array}{l}\text { "An ambient control solution could connect to a building (production control room)'s HVAC (heating, } \\
\text { ventilation, and air conditioning), collect real-time data, and send a signal to all supply chain members via } \\
\text { IoT infrastructures (speed/bandwidth of networks). Data analysis will be fast, which can result not only in } \\
\text { rapid decarbonization of a building but also a rapid return on investment for the company who install } \\
\text { them." (Interviewee H) }\end{array}$ \\
\hline & $\begin{array}{l}\text { "Use of recycling materials for the production of IoT devices can increase the overall sustainability. For } \\
\text { example, promoting the use of recycling material for sensors and mobile devices can reduce solid waste. } \\
\text { Or, use of passive and active sensors for different types of supply chain activities in IoT solutions can } \\
\text { reduce the energy consumption." (Interviewee B) }\end{array}$ \\
\hline \multirow{2}{*}{$\begin{array}{l}\text { Supply Chain } \\
\text { Responsiveness }\end{array}$} & $\begin{array}{l}\text { "Real-time data analysis and response obtained from IoT sensors in warehouse provide improved } \\
\text { inventory tracking and warehouse utilization, optimized corporate operations strategy, and long-term } \\
\text { business partnership with key customers." (Interviewee M) }\end{array}$ \\
\hline & $\begin{array}{l}\text { "IoT solutions use thousands of data collected daily to identify inefficiencies of transport vehicles, which } \\
\text { can then be converted into real energy savings through informed action and real-time response. This can } \\
\text { lead to a rapid transformation in managing supply chain and provide both environmental and financial } \\
\text { benefits." (Interviewee B) }\end{array}$ \\
\hline \multirow[t]{2}{*}{ Human Capital } & $\begin{array}{l}\text { "IoT systems require a high level of technological knowledge, skill, and discipline of human labors. This } \\
\text { results in the development of future workforce strategy consisting of reinventing the HR function, using } \\
\text { flexible working arrangement, and increasing cross-industry and public-private collaboration." } \\
\text { (Interviewee M) }\end{array}$ \\
\hline & $\begin{array}{l}\text { "The higher level of IoT system architecture and complexity implemented in the supply chain, the higher } \\
\text { skill and competence workers is needed. This also leads to reinventing the fundamental education systems } \\
\text { including higher education and life-long learning." (Interviewee D) }\end{array}$ \\
\hline \multirow{2}{*}{$\begin{array}{l}\text { Organizational } \\
\text { Climate and Culture }\end{array}$} & $\begin{array}{l}\text { "Company must have a clear understanding about tradeoff between benefits and costs of IoT systems } \\
\text { because this will help the company develop its budget for big investment, define a roadmap to implement } \\
\text { IoT, keep up the pace of upgrading to new technological developments, and recruit high-skill workers." } \\
\text { (Interviewee T) }\end{array}$ \\
\hline & $\begin{array}{l}\text { "By implementing IoT solutions in the supply chain, all members do not worry much about how often } \\
\text { data will be collected, how much accuracy of the report will be made, and where does data be kept and } \\
\text { shared. This leads to improving the wellbeing of all supply chain members especially in term of the level } \\
\text { of trust and job security." (Interviewee H) }\end{array}$ \\
\hline
\end{tabular}

From Table 9, it can be noted that all of the enabling factors of IoT adoption were validated as relevant and important for the successful IoT adoption for sustainability in supply chain management. Similar to the results from GRA analysis, most interviewees ranked system integration and IoT infrastructure as the most important enabling factors among the five selected factors. Observations from the interviews also confirm that IoT adoption significantly supports three dimensions of supply chain sustainability, including economic, environmental, and social sustainability. Based on technological perspectives (i.e., system integration and IoT infrastructure), IoT systems can mainly provide efficient real-time data analysis, better communication, and a faster and more accurate decisionmaking capability. Further economic and environmental sustainability developments obtained from IoT adoption are the developments of strategic operating and maintenance 
plans and recycling material utilization. This could result in increased longer asset life and return on investment and reduced energy consumption and solid waste. On the other hand, based on organizational perspectives (i.e., supply chain responsiveness, human capital, and organizational climate and culture), IoT systems provide social sustainability benefits from creating long-term business relationships with key partners, increasing industry collaboration, reinventing HR function such as promoting life-long learning and increasing workforce engagement and level of trust. Moreover, interviewees also indicated that their companies gradually invested in some parts of IoT systems and adopted a phased approach due to the high investment cost of systems involved in large projects although they wanted to receive the full technological capabilities sooner.

\section{Findings and Discussion}

From the perspective of each performance measure with respect to each enabling factor, rankings were found to be within the range of $73 \%$ to $94 \%$, suggesting a very high level of IoT success could be achieved, based on all the key performance measures considered with supply chain sustainability. When the importance and priorities of enabling factors of IoT adoption from the sustainability perspective are considered, system integration and IoT infrastructure are the most important enabling factors, followed by all other organizational-related factors. In other words, the most important enabling factors are those directly associated with IoT technology and infrastructure (Systems Integration and IoT Infrastructure). This is supported by a resource-based view on firms at an early stage of IoT diffusion, particularly when SMEs are characterized by having distinct pre-conditions and conditions for IoT/Industry 4.0 [87]. Therefore, the implication is that IoT technology and infrastructure-related factors are more important than organizational-related factors. This could be aligned with the notion that IoT adoption is still an early stage of maturity, particularly in the context of emerging economies. This is further supported by studies indicating that priorities and importance of IoT enabling factors are dependent on the level of IoT maturity $[1,22]$. This also suggests that the IoT technology and infrastructure need to be developed first for the success of IoT adoption. Therefore, prioritizing enabling factors for the success of IoT adoption is critical in emerging economies since many organizations of supply chains are limited with the financial resources required for IoT adoption from a sustainability perspective.

Although organizational climate and culture, supply chain responsiveness, and human capital are less significant compared to technology and infrastructure-related factors, they are also important for the overall success of IoT adoption, as evidenced from the overall improvement in logistics performance [88] and priorities of the organization for digitalization [89]. The findings from the interviews showed that technology-related enabling factors are more important than organizational-related factors, as evidenced by improved overall sustainability from both economic benefits and environmental conditions perspectives. The interviews also indicated the real-time data access and related analyses of various situations achieved through IoT adoption across several cross-functional areas contributing to improved sustainability in supply chains. Similarly, organizational climate and culture and human capital were emphasized by the interviewees as important IoT enabling factors, as well as interdependencies among those factors, particularly the need for high-skill workers and knowledge. Therefore, interdependencies among enabling factors must be identified as part of the overall assessment enabling factors of IoT adoption, beyond the relative importance and prioritization. Some studies have identified interdependencies of broader IoT adoption enabling factors but are limited to focusing only on improving economic benefits and/or limited industry sector, such as improving investment in IoT adoption in the oil and gas industry [90].

\section{Conclusions}

This study identified and ranked the enabling factors for successful IoT adoption with supply chain sustainability. It also identified the key performance measures that relate 
to IoT adoption in the supply chain sustainability context. For the purpose of ranking enabling factors, it was assumed that each performance measure is equally related to IoT implementation. Based on both quantitative (i.e., prioritization of enabling factors using GRA) and qualitative (i.e., validation of enabling factors using semi-structured interviews) analyses, the study found that system integration and IoT infrastructure were the most important enabling factors for IoT adoption with supply chain sustainability. Conversely, organizational climate and culture, supply chain responsiveness, and human capital were the lowest ranked enabling factors. Interviews with key industry experts/executives from different Thai manufacturing organizations indicated that the key priority is now to get the technology and hardware for IoT right. Therefore, while other enabling factors such as organizational climate and culture, supply chain responsiveness, and human capital have a role to play in IoT adoption, they do not appear to be the main focus at this stage of the evolution of IoT systems.

This study suggests that organizations are seeking to deploy the IoT need, at this time in its evolution, to focus mainly on getting the technology and infrastructure right, as system integration and IoT infrastructure are found to be the highest priority enabling factors for IoT adoption evaluated through performance rankings of each enabling factor associated with supply chain sustainability. Thus, the novelty of this research is attributed to prioritizing enabling factors in implementing IoT based on the concept of sustainability (triple bottom line). It also demonstrates the relative importance of each factor to achieve the IoT implementation objectives where IoT diffusion is in an early stage. At the same time, organizations also need to follow with other softer aspects of technology deployment and change management after implementing IoT systems for some time. Because IoT systems require a high level of technological knowledge, workforce skills, and investment costs and IoT technologies are constantly and quickly evolving, the managerial implications for company management are as follows:

- Needs to reinvent HR function, training program curriculum, and university-industry or industry-industry collaboration.

- Invests in upskilling and reskilling programs for the workforces.

- Cultivates a culture of continuous or life-long learning for the workforce.

- Performs continuous development of inclusive partnerships with various upstream and downstream companies.

- Builds IoT-compatible systems and devices based on common trust and engagement among supply chain partners.

Similarly, the managerial implications for policy makers, i.e., government and its regulatory agency, are as follows:

- Needs to be more agile and proactive in setting standards for IoT solutions so that organizations can start to invest in such solutions.

- Redesigns government incentives, tax benefits, and other related grants to stimulate IoT investment.

- Develops government initiatives for start-ups to facilitate various stages of IoT platforms development.

This study also has managerial implications for academic research. The findings indicate that industry practitioners/experts are engaging proactively with IoT adoption and therefore, academic research needs to be focused on implementation challenges. Hence, academic research needs to proactively anticipate and address challenges that will be faced at each level of IoT development as the technology evolves. Due to the fast-growing technologies in IoT solutions, academic institutions need to constantly reinvent up-to-date science and technology curriculums. In addition, the national higher education system must be redesigned to engage in life-long learning because newly emerging IoT technology is constantly changing.

This research study has a few limitations. It is limited by the scope of enabling factors considered. There may be other factors that impact IoT adoption with sustainability that 
have not been considered in this study. Since IoT technology is around an early stage of evolution and it will face challenges as it develops, future research should explore more enabling factors, priorities, and interdependencies among those factors using a range of the manufacturing industry case studies. In addition, data were collected from a limited number of industry practitioners/experts and the interviews were limited to a specific group of industry executives of large companies with both upstream and downstream entities. Therefore, generalization of enabling factors for any industry-specific IoT adoption and applicability of the research findings to IoT adoption in SMEs require further research as this study is limited to inputs from large organizations. In addition, models for implementing IoT and evaluating its success are lacking and could be a focus for future studies.

Author Contributions: Conceptualization, S.P., P.S. and T.L.; methodology, S.P., P.S. and T.L.; validation, P.S. and T.L.; formal analysis, S.P., P.S. and T.L.; writing-original draft preparation, S.P., P.S. and T.L.; writing-review and editing, P.S. and T.L.; project administration, P.S.; funding acquisition, T.L. All authors have read and agreed to the published version of the manuscript.

Funding: This work was supported by Thammasat School of Engineering, Thammasat University, Thailand (004/2563).

Institutional Review Board Statement: Not applicable.

Informed Consent Statement: Not applicable.

Data Availability Statement: Data used for the analyses are available upon request.

Acknowledgments: All industry experts and executives from various Thai manufacturing companies are thanked for their valuable research inputs. We also would like to thank Thammasat School of Engineering, Thammasat University for the research funding and School of Engineering, King Mongkut's Institute of Technology Ladkrabang for financial support for publication.

Conflicts of Interest: The authors declare no conflict of interest.

\begin{tabular}{ll}
\multicolumn{2}{l}{ Abbreviations } \\
CPS & Cyber-physical systems \\
IoT & Internet of Things \\
IoS & Internet of Service \\
AI & Artificial intelligence \\
IIoT & Industrial Internet of Things \\
TBL & Triple bottom line \\
MCDM & Multiple criteria decision-making \\
AHP & Analytic hierarchy process \\
RFID & Radio frequency identification \\
DEMATEL & Decision-making trial and evaluation laboratory \\
SME & Small to medium-sized enterprise \\
GRA & Grey relational analysis \\
SCM & Supply chain management \\
I4.0 & Industry 4.0 \\
SI & System integration \\
IoTI & IoT infrastructure \\
SCR & Supply chain responsiveness \\
HC & Human capital \\
OCC & Organizational climate and culture \\
MBA & Master of Business Administration \\
MSc & Master of Science \\
HVAC & Heating, ventilation, and air conditioning \\
HR & Human resource \\
&
\end{tabular}




\section{References}

1. Maisiri, W.; Dyk, L.V.; Coeztee, R. Factors that inhibit sustainable adoption of Industry 4.0 in the South African manufacturing industry. Sustainability 2021, 13, 1013. [CrossRef]

2. Li, G.; Hou, Y.; Wu, A. Fourth industrial revolution: Technological drivers, impacts and coping methods. Chin. Geogr. Sci. 2017, 27, 626-637. [CrossRef]

3. Waibel, M.W.; Steenkamp, L.P.; Moloko, N.; Oosthuizen, G.A. Investigating the effects of smart production systems on sustainability elements. Procedia Manuf. 2017, 8, 731-737. [CrossRef]

4. Pereira, A.; Romero, F. A review of the meanings and the implications of the Industry 4.0 concept. Procedia Manuf. 2017, 13, 1206-1214. [CrossRef]

5. Jeschke, S.; Brecher, C.; Song, H.; Rawat, D.B. Industrial Internet of Things Cybermanufacturing Systems; Springer: Cham, Switzerland, 2017; pp. 3-19.

6. Wu, L.; Yue, X.; Jin, A.; Yen, D.C. Smart supply chain management: A review and implications for future research. Int. J. Logist. Manag. 2016, 27, 395-417. [CrossRef]

7. Kamble, S.S.; Gunasekaran, A.; Gawankar, S.A. Sustainable Industry 4.0 framework: A systematic literature review identifying the current trends and future perspectives. Process Saf. Environ. Prot. 2018, 117, 408-425. [CrossRef]

8. Lee, I.; Lee, K. The Internet of Things (IoT): Applications, investments, and challenges for enterprises. Bus. Horiz. 2015, 58, 431-440. [CrossRef]

9. Robinson, A. The Future of Supply Chain, Logistics \& Manufacturing: How Technology is Transforming Industries. Available online: http:/ / cerasis.com/wp-content/uploads/2015/12/TechnologyManufacturingSupplyChainLogisticseBook.pdf (accessed on 5 December 2015).

10. Felsberger, A.; Qaiser, F.; Choudhary, A.; Reiner, G. The impact of Industry 4.0 on the reconciliation of dynamic capabilities: Evidence from the European manufacturing industries. Prod. Plan. Control 2020. [CrossRef]

11. Müller, J.M.; Kiel, D.; Voigt, K.I. What drives the implementation of Industry 4.0? The role of opportunities and challenges in the context of sustainability. Sustainability 2018, 10, 247. [CrossRef]

12. Elkington, J. Partnerships from cannibals with forks: The triple bottom line of 21st-century business. Environ. Qual. Manag. 1998, 8, 37-51. [CrossRef]

13. Sony, M.; Naik, S. Critical factors for the successful implementation of Industry 4.0: A review and future research direction. Prod. Plan. Control 2020, 31, 799-815. [CrossRef]

14. Nwaiwu, F.; Duduci, M.; Chromjakova, F.; Otekhile, C.F. Industry 4.0 concepts within the Czech SME manufacturing sector: An empirical assessment of critical success factors. Bus. Theory Pract. 2020, 21, 58-70. [CrossRef]

15. De Sousa Jabbour, A.B.L.; Jabbour, C.J.C.; Foropon, C.; Filho, M.G. When Titans meet-Can Industry 4.0 revolutionise the environmentally-sustainable manufacturing wave? The role of critical success factors. Technol. Forecast. Soc. Chang. 2018, 132, 18-25. [CrossRef]

16. Cañas, H.; Mula, J.; Campuzano-Bolarín, F. A general outline of a sustainable supply chain 4.0. Sustainability 2020, $12,7978$. [CrossRef]

17. Ben-Daya, M.; Hassini, E.; Bahroun, Z. Internet of things and supply chain management: A literature review. Int. J. Prod. Res. 2017, 7543, 1-24. [CrossRef]

18. Shin, S.; Woo, J.; Rachuri, S. Predictive analytics model for power consumption in manufacturing predictive analytics model for power consumption in manufacturing. Procedia CIPR 2014, 15, 153-158. [CrossRef]

19. Ruggieri, A.; Braccini, A.M.; Poponi, S.; Mosconi, E.M. A Meta-Model of inter-organisational cooperation for the transition to a circular economy. Sustainability 2016, 8, 1153. [CrossRef]

20. Zhang, Y.; Liu, S.; Liu, Y.; Yang, H.; Li, M.; Huisingh, D.; Wang, L. The 'Internet of Things' enabled real-time scheduling for remanufacturing of automobile engines. J. Clean. Prod. 2018, 185, 562-575. [CrossRef]

21. Braccini, A.M.; Margherita, E.G. Exploring organizational sustainability of Industry 4.0 under the Triple Bottom Line: The case of a manufacturing company. Sustainability 2019, 11, 36. [CrossRef]

22. Gotmare, A.; Bokade, S.; Bhirud, S.G. Analyzing the barriers to Internet of Things (IoT) adoption in Indian manufacturing firms using analytical hierarchy process. Udyog Pragati 2021, 42, 12-24.

23. Lin, L.C. An integrated framework for the development of radio frequency identification technology in the logistics and supply chain management. Comput. Ind. Eng. 2009, 57, 832-842. [CrossRef]

24. Hsu, C.W.; Yeh, C.C. Understanding the factors affecting the adopting of the Internet of Things. Technol. Anal. Strateg. Manag. 2017, 29, 1089-1102. [CrossRef]

25. Asir, T.R.G.; Sivaranjani, K.N.; Anandaraj, W. Internet of Things and India's readiness. Int. J. Appl. Eng. Res. 2015, 10, 274-279.

26. Stentoft, J.; Adsbøll Wickstrøm, K.; Philipsen, K.; Haug, A. Drivers and barriers for Industry 4.0 readiness and practice: Empirical evidence from small and medium-sized manufacturers. Prod. Plan. Control 2020, 32, 1-18. [CrossRef]

27. Boyes, H.; Hallaq, B.; Cunningham, J.; Watson, T. The Industrial Internet of Things (IIoT): An analysis framework. Comput. Ind. 2018, 101, 1-12. [CrossRef]

28. Ammar, M.; Russello, G.; Crispo, B. Internet of Things: A survey on the security of IoT frameworks. J. Inf. Secur. Appl. 2018, 38, 8-27. [CrossRef]

29. Li, S.; Da Xu, L.; Zhao, S. 5G Internet of Things: A survey. J. Ind. Inf. Integr. 2018, 10, 1-9. [CrossRef] 
30. Kassab, W.; Darabkh, K.A. A-Z survey of Internet of Things: Architectures, protocols, applications, recent advances, future directions and recommendations. J. Netw. Comput. Appl. 2020, 163, 102663. [CrossRef]

31. Kiel, D.; Arnold, C.; Voigt, K.I. The influence of the Industrial Internet of Things on business models of established manufacturing companies-A business level perspective. Technovation 2017, 68, 4-19. [CrossRef]

32. $\mathrm{Da} \mathrm{Xu,} \mathrm{L.;} \mathrm{He,} \mathrm{W.;} \mathrm{Li,} \mathrm{S.} \mathrm{Internet} \mathrm{of} \mathrm{things} \mathrm{in} \mathrm{industries:} \mathrm{A} \mathrm{survey.} \mathrm{IEEE} \mathrm{Trans.} \mathrm{Ind.} \mathrm{Informat.} \mathrm{2014,} \mathrm{10,} 2233-2243$.

33. Arnold, C.; Voigt, K.I. Ecosystem effects of the Industrial Internet of Things on manufacturing companies. Acta Infol. 2017, 1, 99-108.

34. Yerra, V.A.; Pilla, S. IIoT-Enabled production system for composite intensive vehicle manufacturing. SAE Int. J. Eng. 2017, 10, 209-214. [CrossRef]

35. Aish, S.; Chakraborty, S.; Sain, M.; Lee, H.I.; Kim, H.C. A review on benefits of IoT integrated blockchain based supply chain management implementations across different sectors with case study. In Proceedings of the 2019 21st International Conference on Advanced Communication Technology (ICACT), PyeongChang, Korea, 17-20 February 2019; pp. 138-141.

36. Tu, M. An exploratory study of Internet of Things (IoT) adoption intention in logistics and supply chain management: A mixed research approach. Int. J. Logist. Manag. 2018, 29, 131-151. [CrossRef]

37. Mostafa, N.; Hamdy, E.; Awady, H. Impacts of Internet of Things on supply chain: A framework for warehousing. Soc. Sci. 2019, 8, 84. [CrossRef]

38. Tejesh, B.; Subrahmanya, S.; Roy, K.S. A low-cost warehouse inventory management system using internet of things and open source hardware. Int. J. Control. Theory Appl. 2017, 10, 113-122.

39. Hu, S.; Hu, B.; Cao, Y. The wider, the better? The interaction between the IoT diffusion and online retailers' decisions. Phys. A Stat. Mech. Appl. 2018, 509, 196-209. [CrossRef]

40. Tahiliani, V.; Digalwar, M. Green IoT systems: An energy efficient perspective. In Proceedings of the 2018 Eleventh International Conference on Contemporary Computing (IC3), Noida, India, 2-4 August 2018.

41. Gapchup, A.; Wani, A.; Gapchup, D.; Jadhav, S. Health care systems using Internet of Things. Int. J. Innov. Res. Comput. Commun. Eng. 2016, 4, 155-172.

42. Ghosh, A. IoT based agricultural features for supporting farmers. Int. J. Innov. Eng. Res. Technol. 2020, 7, 188-192.

43. Felsberger, A.; Reiner, G. Sustainable Industrial 4.0 in production and operations management: A systematic literature review. Sustainability 2020, 12, 7982. [CrossRef]

44. Jamwal, A.; Agrawal, R.; Sharma, M.; Giallanza, A. Industry 4.0 technologies for manufacturing sustainability: A systematic review and future research directions. Appl. Sci. 2021, 11, 5725. [CrossRef]

45. Vass, T.D.; Shee, H.; Miah, S.J. IoT in supply chain management: A narrative on retail sector sustainability. Int. J. Logist. Res. Appl. 2020, 24, 1-20.

46. Narula, S.; Puppula, H.; Kumar, A.; Frederico, G.F.; Dwivedy, M.; Prakash, S.; Talwar, V. Applicability of Industry 4.0 technologies in the adoption of global reporting initiative standards for achieving sustainability. J. Clean. Prod. 2021, 305. [CrossRef]

47. Vrchota, J.; Pech, M.; Rolínek, L.; Bednář, J. Sustainability outcomes of green processes in relation to Industry 4.0 in manufacturing: Systematic review. Sustainability 2020, 12, 5968. [CrossRef]

48. Brozzi, R.; Forti, D.; Rauch, E.; Matt, D.T. The advantages of Industry 4.0 applications for sustainability: Results from a sample of manufacturing companies. Sustainability 2020, 12, 3647. [CrossRef]

49. Varela, L.; Araújo, A.; Ávila, P.; Castro, H.; Putnik, G. Evaluation of the relation between lean manufacturing, Industry 4.0, and sustainability. Sustainability 2019, 11, 1439. [CrossRef]

50. Ghobakhloo, M. Industry 4.0, digitization, and opportunities for sustainability. J. Clean. Prod. 2020, 252, 119869. [CrossRef]

51. Adebiyi, O.O.; Cruz, M.T.D. Green sustainability development for Industry Internet of Things in railway transportation industry. Int. J. Trend Sci. Res. Dev. 2017, 203-208. [CrossRef]

52. Frank, A.G.; Dalenogare, L.S.; Ayala, N.F. Industry 4.0 technologies: Implementation patterns in manufacturing companies. Int. J. Prod. Econ. 2019, 210, 15-26. [CrossRef]

53. Tripathi, S.; Pandit, L. Analysis of factors influencing adoption of Internet of Things: A system dynamics approach. Theor. Econ. Lett. 2019, 9, 2606-2625. [CrossRef]

54. Nord, J.H.; Koohang, A.; Paliszkiewicz, J. The Internet of Things: Review and theoretical framework. Expert Syst. Appl. 2019, 133, 97-108. [CrossRef]

55. Roy, A.; Zalzala, A.M.S.; Kumar, A. Disruption of things: A model to facilitate adoption of IoT-based innovations by the urban poor. Procedia Eng. 2016, 159, 199-209. [CrossRef]

56. Haddud, A.; DeSouza, A.; Khare, A.; Lee, H. Examining potential benefits and challenges associated with the Internet of Things integration in supply chains. J. Manuf. Technol. Manag. 2017, 28, 1055-1085. [CrossRef]

57. Kubler, S.; Robert, J.; Derigent, W.; Voisin, A.; Traon, Y.L. A state-of the-art survey \& testbed of fuzzy AHP (FAHP) applications. Expert Syst. Appl. 2016, 65, 1-25.

58. Wang, T.K.; Zhang, Q.; Chong, H.Y.; Wang, X. Integrated supplier selection framework in a resilient construction supply chain: An approach via analytic hierarchy process (AHP) and grey relational analysis (GRA). Sustainability 2017, 9, 289. [CrossRef]

59. Laosirihongthong, T.; Samaranayake, P.; Nagalingam, S. A holistic approach to supplier evaluation and order allocation towards sustainable procurement. Benchmarking 2019, 26, 2543-2573. [CrossRef] 
60. Tseng, M.L.; Lin, Y.H.; Chiu, A.S. Fuzzy AHP-based study of cleaner production implementation in Taiwan PWB manufacturer. J. Clean. Prod. 2009, 17, 1249-1256. [CrossRef]

61. Gnanasekaran, S.; Velappan, S.; Sivasangari, A. Development of a supplier selection system by combining Analytic Hierarchy Process and Grey Relational Analysis: An automobile industry case study. J. Supply Chain Manag. 2008, 5, 82-94.

62. Bogataj, D.; Bogataj, M.; Hudoklin, D. Mitigating risks of perishable products in the cyber-physical systems based on the extended MRP model. Int. J. Prod. Econ. 2017, 193, 51-62. [CrossRef]

63. Dweekat, A.J.; Hwang, G.; Park, J. A supply chain performance measurement approach using the Internet of Things: Toward more practical SCPMS. Ind. Manag. Data Syst. 2017, 117, 267-286. [CrossRef]

64. Del Giudice, M. Discovering the Internet of Things (IoT) within the business process management: A literature review on technological revitalization. Bus. Process Manag. J. 2016, 22, 263-270. [CrossRef]

65. Kache, F.; Seuring, S. Challenges and opportunities of digital information at the intersection of big data analytics and supply chain management. Int. J. Oper. Prod. Manag. 2017, 37, 10-36. [CrossRef]

66. Yu, W.; Ramanathan, R.; Wang, X.; Yang, J. Operations capability, productivity and business performance: The moderating effect of environmental dynamism. Ind. Manag. Data Syst. 2018, 118, 126-143. [CrossRef]

67. Rymaszewska, A.; Helo, P.; Gunasekaran, A. IoT powered servitization of manufacturing-an exploratory case study. Int. J. Prod. Econ. 2017, 192, 92-105. [CrossRef]

68. Mishra, D.; Gunasekaran, A.; Childe, J.S.; Papadopoulos, T.; Dubey, R.; Wamba, S. Vision, applications and future challenges of Internet of Things: A bibliometric study of the recent literature. Ind. Manag. Data Syst. 2016, 116, 1331-1355. [CrossRef]

69. Parry, G.C.; Brax, S.A.; Maull, R.S.; Ng, I.C.L. Operationalising IoT for reverse supply: The development of use-visibility measures. Int. J. Supply Chain Manag. 2016, 21, 228-244. [CrossRef]

70. Strozzi, F.; Colicchia, C.; Creazza, A.; Noè, C. Literature review on the 'Smart Factory' concept using bibliometric tools. Int. J. Prod. Res. 2017, 55, 6572-6591. [CrossRef]

71. Tu, M.; Lim, M.K.; Yang, M.F. IoT-based production the supply chain and supply chain system-Part 2: IoT-based cyber-physical system: A framework \& evaluation. Ind. Manag. Data Syst. 2018, 118, 96-125.

72. Yan, R. Optimization approach for increasing revenue of perishable product supply chain with the Internet of Things. Ind. Manag. Data Syst. 2017, 117, 729-741. [CrossRef]

73. Weinberg, B.D.; Milne, G.R.; Andonova, Y.G.; Hajjat, F.M. Internet of Things: Convenience vs. privacy and secrecy. Bus. Horiz. 2015, 58, 615-624. [CrossRef]

74. Strange, R.; Zucchella, A. Industry 4.0, global value chains and international business. Multinatl. Bus. Rev. 2017, 25, 174-184 [CrossRef]

75. Noura, M.; Atiquzzaman, M.; Gaedke, M. Interoperability in Internet of Things: Taxonomies and open challenges. Mob. Netw. Appl. 2019, 24, 796-809. [CrossRef]

76. Yacob, A.; Baharum, Z.; Aziz, N.; Sulaiman, N.S.; Hamzah, W.M.A.F.W. A review of Internet of Things (IoT): Implementation and challenges. Int. J. Adv. Trends Comput. Sci. Eng. 2020, 9, 373-376. [CrossRef]

77. Siddiqui, M.A.; Asim, M.; Mazoor, S. Implementing Industry 4.0 in global perspective: A challenge for managing inter-country supply chain. Glob. Sci. J. 2020, 8, 3838-3861.

78. Trzaskoma, B. Critical Success Factors for IoT Implementation, and How They Differ for Organizations with Low Digital Maturity. Master's Dissertation, Universidade Catolica Portuguesa, Lisboa, Portugal, 15 June 2020.

79. Olushola, O.B. Factors affecting IoT adoption. IOSR J. Comput. Eng. 2019, 21, 19-24.

80. Lak, B.; Rezaeenour, J. Maturity assessment of social customer knowledge management (sckm) using fuzzy expert system. J. Bus. Econ. Manag. 2018, 19, 192-212. [CrossRef]

81. Kagermann, H.; Wahlster, W.; Helbig, J. Recommendations for Implementing the Strategic Initiative Industry 4.0: Final report of the Industry 4.0 Working Group; Communication Promoters Group of the Industry-Science Research Alliance, Acatech: Frankfurt am Main, Germany, 2013.

82. Martins, R.; Oliveira, T.; Thomas, M.A. An empirical analysis to assess the determinants of SaaS diffusion in firms. Comput. Hum. Behav. 2016, 62, 19-33. [CrossRef]

83. Marques, M.; Agostinho, C.; Zacharewicz, G.; Jardim-Gonçalves, R. Decentralized decision support for intelligent manufacturing in Industry 4.0. J. Ambient Intell. Smart Environ. 2017, 9, 299-313. [CrossRef]

84. Yang, C.C.; Chen, B.S. Supplier selection using combined analytical hierarchy process and grey relational analysis. J. Manuf. Technol. Manag. 2006, 17, 926-941. [CrossRef]

85. Chen, C.-H. A new multi-criteria assessment model combining GRA techniques with intuitionistic fuzzy entropy based TOPSIS method for sustainable building materials supplier selection. Sustainability 2019, 11, 2265. [CrossRef]

86. Maniya, K.D.; Bhatt, M.G. A multi-attribute selection of automated guided vehicle using the AHP/M-GRA technique. Int. J. Prod. Res. 2011, 49, 6107-6124. [CrossRef]

87. Estensoro, M.; Larrea, M.; Müller, J.M.; Sisti, E. A resource-based view on SMEs regarding the transition to more sophisticated stages of Industry 4.0. Eur. Manag. J. 2021. [CrossRef]

88. Wong, W.P.; Tang, C.F. The major determinants of logistic performance in a global perspective: Evidence from panel data analysis. Int. J. Logist. Res. Appl. 2018, 21, 431-443. [CrossRef] 
89. Muñoz-Flores, C.H.; Olivella-Nadal, J. Enablers and inhibitors for IoT implementation. In Internet of Things; Márquez, F.P.G., Lev, B., Eds.; Springer: Cham, Switzerland, 2021; pp. 25-48.

90. Hawash, B.; Mokhtar, U.A.; Yusof, Z.M.; Mukred, M.; Gaid, A.S. Factors affecting Internet of Things (IoT) adoption in the Yemeni oil and gas sector. In Proceedings of the 2021 International Conference of Technology, Science and Administration (ICTSA), Taiz, Yemen, 22-24 March 2021; pp. 1-7. 